E. A. Kiselev', P. Gaczynski ${ }^{\mathrm{b}}$, G. Eckold ${ }^{\mathrm{c}}$, A. Feldhoff ${ }^{\mathrm{d}}$, K.-D. Becker ${ }^{\mathrm{b}}$, V. A. Cherepanov ${ }^{\mathrm{a}}$

${ }^{a}$ Department of Physical and Inorganic Chemistry, Institute of Natural Sciences and Mathematics, Ural Federal University, Kuybysheva St. 48, 620026, Yekaterinburg, Russia ${ }^{b}$ Institute of Physical and Theoretical Chemistry, Technische Universität Braunschweig, Rebenring 56. 10, D-38106, Braunschweig, Germany ' Institute of Physical Chemistry, Georg-August-Universität Göttingen, Tammannstr. 6, 37077, Göttingen, Germany ${ }^{d}$ Institute of Physical Chemistry and Electrochemistry, Leibniz Universität Hannover, Callinstr. 3a, D-30179, Hannover, Germany eugene.kiselyov@urfu.ru

\title{
Investigations into the structure of $\mathrm{La}_{3} \mathrm{Ni}_{2-x} \mathrm{Fe}_{x} \mathrm{O}_{7 \pm \delta}$
}

The room-temperature (RT) ${ }^{57} \mathrm{Fe}$ Mössbauer spectra of the $\mathrm{La}_{3} \mathrm{Ni}_{2-x} \mathrm{Fe}_{x} \mathrm{O}_{7 \pm \delta}$ oxide solid solutions of Ruddlesden-Popper-type $(x=0.05,0.10)$ reveal two doublets for $\mathrm{Fe}^{3+}$ ions in octahedral coordination by oxygen. The existence of two inequivalent sites for Fe at $\mathrm{RT}$ is at variance with the space groups Fmmm and $\mathrm{Cmcm}$ (Amam) which have been reported for $\mathrm{La}_{3} \mathrm{Ni}_{2} \mathrm{O}_{7 \pm \delta}$. This unexpected finding is discussed in connection with Patterson analyses and Rietveld refinements of powder XRD data for $x=0,0.05$, and 0.10. Alternative structural models have been proposed which can explain the spectroscopic findings and which are compatible with the results from $\mathrm{X}$-ray diffraction.

Keywords: $\mathrm{La}_{3} \mathrm{Ni}_{2} \mathrm{O}_{7}$; complex oxides; Ruddlesden-Popper phases; Mössbauer spectroscopy; crystal structure; Patterson analysis; Rietveld refinement.

Received: 15.07.2019. Accepted: 01.08.2019. Published: 05.08.2019.

(C) Kiselev E. A., Gaczynski P., Eckold G., Feldhoff A., Becker K.-D., Cherepanov V. A., 2019

\section{Introduction}

Layered Ruddlesden-Popper (R-P) lanthanum nickelates of the general formula $\mathrm{La}_{n+1} \mathrm{Ni}_{n} \mathrm{O}_{3 n+1}$ have recently been studied for potential application as SOFC cathodes [1-5] for the members with $n=$ $1,2,3$. The structure is characterized by $n$ perovskite-type layers, $\mathrm{n} \cdot \mathrm{LaNiO}_{3}$, stacked up in c-direction and separated by a single rock-salt-type layer of $\mathrm{LaO}, \mathrm{LaO}\left(\mathrm{LaNiO}_{3}\right)_{n}$. Presently, however, $\mathrm{La}_{2} \mathrm{NiO}_{4+\delta}$ with $n=1$ is the most studied within the series; data concerning $\mathrm{La}_{3} \mathrm{Ni}_{2} \mathrm{O}_{7 \pm \delta}$ and $\mathrm{La}_{4} \mathrm{Ni}_{3} \mathrm{O}_{10-\delta}$ are still insufficient and sometimes contradictory. In the present paper, the focus will be on $\mathrm{La}_{3} \mathrm{Ni}_{2} \mathrm{O}_{7 \pm \delta}(n=2)$.
$\mathrm{La}_{3} \mathrm{Ni}_{2} \mathrm{O}_{7+\delta}$ was first reported by Brisi et al. [6] as an intermediate phase in an attempt to synthesize $\mathrm{La}_{4} \mathrm{Ni}_{3} \mathrm{O}_{10-\delta}$ at $1100^{\circ} \mathrm{C}$. Drennan et al. [7] could directly obtain the $n=2$ compound by annealing at $1150{ }^{\circ} \mathrm{C}$ in air for $5 \mathrm{~h}$ with intermediate re-grindings. The unit-cell parameters were approximately determined as $a=5.42 \AA$, $b=5.47 \AA$, and $c=20.58 \AA$. However, electron microscopy revealed intergrowth of all members of the series with $n=2,3$, and 4. Later, the existence of $\mathrm{La}_{3} \mathrm{Ni}_{2} \mathrm{O}_{7 \pm \delta}$ was confirmed by Odier et al. [8] in the temperature range $900-1150^{\circ} \mathrm{C}$. However, small amounts of secondary phases were 
still found present. Mohan Ram et al. [9] obtained $\mathrm{La}_{3} \mathrm{Ni}_{2} \mathrm{O}_{7 \pm \delta}$ by decomposing stoichiometric amounts of lanthanum and nickel nitrates and annealing at $1420 \mathrm{~K}$ for $10 \mathrm{~h}$ with frequent grindings. Although the X-ray diffraction patterns showed no evidence for the presence of other members of the series, HREM studies showed intergrowth of small extent of members with $n=3$ and $n=5$. Similar problems were also reported by Sreedhar et al. [10] who stated that intergrowth can be minimized by annealing samples at a suitable temperature $\left(1150{ }^{\circ} \mathrm{C}\right)$. According to Zhang et al. [11], single phase $\mathrm{La}_{3} \mathrm{Ni}_{2} \mathrm{O}_{7 \pm \delta}$ can be obtained by solution synthesis followed by heat treatment and final annealing of the pressed pellets for $4-5$ days at $1150-1200^{\circ} \mathrm{C}$. These authors determined the oxygen content of the as-prepared $n=$ 2 lanthanum nickelate by iodometric titration and TGA to $\mathrm{La}_{3} \mathrm{Ni}_{2} \mathrm{O}_{6.92}[11]$.

Zhang et al. [11] were the first to refine (X-ray) diffraction data of $\mathrm{La}_{3} \mathrm{Ni}_{2} \mathrm{O}_{6.92}$ in the orthorhombic space group Fmmm which provides only a single site for nickel cations. This space group was also used by Carvalho et al. [12] in their refinement of the unit-cell parameters of the compound. These authors also showed that the oxygen content of as prepared samples depends on the synthesis route: nitrate precursors usually were found to yield oxygen-deficient materials, e.g. $\mathrm{La}_{3} \mathrm{Ni}_{2} \mathrm{O}_{6.93}$ which is close to results reported in Ref. [11]. On the other hand, slightly oxygen excess samples, e. g. $\mathrm{La}_{3} \mathrm{Ni}_{2} \mathrm{O}_{7.03}$, could be produced by the citrate technique. Generally, least-square refinements of XRD data within the Fmmm space group showed good agreement in the unit cell parameters [1, 11-13]. However, neutron diffraction data by Ling et al. [14] on $\mathrm{La}_{3} \mathrm{Ni}_{2} \mathrm{O}_{7.02}$ and $\mathrm{La}_{3} \mathrm{Ni}_{2} \mathrm{O}_{7.05}$ revealed a number of weak but clearly resolved peaks which could not be indexed by the Fmmm structural model, but could satisfactorily be refined within the Amam space group (a nonstandard setting of the $\mathrm{Cmcm}$ space group). The main features of this structure, which also provides a single unique site for nickel, are significantly distorted $\mathrm{NiO}_{6}$ octahedra and an elongation of $\mathrm{Ni}-\mathrm{O}$ bonds in $c$-direction towards to the rock salt layers [14]. These results were confirmed by Voronin et al. [15] using single-phase $\mathrm{La}_{3} \mathrm{Ni}_{2} \mathrm{O}_{7 \pm \delta}$. In this work, the standard $\mathrm{Cmcm}$ space group was used for refinement of neutron diffraction data and for EXAFS spectral analysis. The unit cell parameters and the oxygen content of the $\mathrm{La}_{3} \mathrm{Ni}_{2} \mathrm{O}_{7 \pm \delta}$ powder samples obtained by various authors $[1,6,7,9-17]$ are listed in Table 1 for comparison. The temperature dependence of the oxygen content of the $n=2 \mathrm{R}-\mathrm{P}$ compound in air has been studied by Bannikov and Cherepanov [16] in the temperature range $900-1150^{\circ} \mathrm{C}$. It was shown that the stoichiometric parameter $\delta$ of $\mathrm{La}_{3} \mathrm{Ni}_{2} \mathrm{O}_{7-\delta}$ changes from about 0.057 at $900{ }^{\circ} \mathrm{C}$ to 0.072 at $1150{ }^{\circ} \mathrm{C}$ which is in good agreement with the results presented in Refs. [1, 11, 12] for the samples prepared by nitrate route, Table 1 .

At elevated temperatures, $\mathrm{La}_{3} \mathrm{Ni}_{2} \mathrm{O}_{7 \pm \delta}$ has been found to undergo a structural phase transition. Sasaki et al. [13] observed a discontinuous change in the temperature dependence of the lattice parameter for the $c$-axis of the unit cell at about $550 \mathrm{~K}$. The transition has also been detected in lattice expansion [1], in magnetic [18], infrared [19], electrical conductivity $[1,18,19]$, and in thermal measurements $[18,20]$. From all these experiments, transition temperatures between 550 and $600 \mathrm{~K}$ have been reported. More recently, Amow et al. [1] monitored changes in the hightemperature $\mathrm{X}$-ray diffraction patterns 
of $\mathrm{La}_{3} \mathrm{Ni}_{2} \mathrm{O}_{6.95}$ which led them to the conclusion that at about $590 \mathrm{~K}$ a transformation occurs from orthorhombic Fmmm to a higher symmetry tetragonal phase.

Mössbauer spectroscopy has already been applied to the neighboring Ruddlesden-Popper phases $\mathrm{La}_{2} \mathrm{Ni}_{x} \mathrm{Fe}_{1-x} \mathrm{O}_{4+\delta}(n=1)$ [21-24] and $\mathrm{La}_{4} \mathrm{Ni}_{3-x} \mathrm{O}_{10-\delta}(n=3)$ [24-26] in a number of studies. The ${ }^{57} \mathrm{Fe}$ Mössbauer spectra of these compounds are composed of one and of two doublets, respectively. This observation is in full agreement with the layered structures of these compounds which provide one unique site and two non-equivalent sites for nickel in the R-P phases with $n=1$ and $n=3$, respectively. This has been considered strong evidence for the conjecture that $\mathrm{Fe}$ is incorporated on the transition metal sites in the R-P lanthanum nickelates. Under this condition - and provided that $\mathrm{La}_{3} \mathrm{Ni}_{2-x} \mathrm{Fe}_{x} \mathrm{O}_{7 \pm \delta}$ crystallizes in space group Fmmm or Cmcm (Amam) - the Mössbauer spectrum of $\mathrm{La}_{3} \mathrm{Ni}_{2-x} \mathrm{Fe}_{x} \mathrm{O}_{7 \pm \delta}$ is expected to consist of a single signal only.

Among the layered Ruddlesden-Popper lanthanum nickelates, $\mathrm{La}_{3} \mathrm{Ni}_{2} \mathrm{O}_{7 \pm \delta}$ is special in that the average oxidation state of nickel cations for the stoichiometric composition with $\delta=0$ is 2.5 , indicating equal number of $\mathrm{Ni}^{2+}$ and $\mathrm{Ni}^{3+}$ ions. At low temperatures, this can open the possibility for charge ordering of the nickel cations. Nevertheless, all structural models existing to date for $\mathrm{La}_{3} \mathrm{Ni}_{2} \mathrm{O}_{7 \pm \delta}$ (Fmmm [1, 11-13], Amam [14], and $\mathrm{Cmcm}$ [15]) do not account for this special aspect in providing only a single site for Ni. The present Mössbauer study was undertaken in order to shed light into the local structure of $\mathrm{La}_{3} \mathrm{Ni}_{2-x} \mathrm{Fe}_{x} \mathrm{O}_{7 \pm \delta}$. In contrast to the neighboring $\mathrm{R}-\mathrm{P}$ phases $\mathrm{La}_{2} \mathrm{Ni}_{1-x} \mathrm{Fe}_{x} \mathrm{O}_{4+\delta}$ and $\mathrm{La}_{4} \mathrm{Ni}_{3-x} \mathrm{Fe}_{x} \mathrm{O}_{10-\delta}$ which have already been well studied by Mössbauer spectroscopy [21-26], the present work to our knowledge appears to be the first Mössbauer study of $\mathrm{La}_{3} \mathrm{Ni}_{2-x} \mathrm{Fe}_{x} \mathrm{O}_{7 \pm \delta}$.

Table 1

Structural data of $\mathrm{La}_{3} \mathrm{Ni}_{2} \mathrm{O}_{7 \pm \delta}$ obtained from X-ray and neutron diffraction, RT

\begin{tabular}{|c|c|c|c|c|c|}
\hline$a(\AA)$ & $b(\AA)$ & $c(\AA)$ & Space group & $\begin{array}{c}\text { Oxygen } \\
\text { content } 7 \pm \delta\end{array}$ & Ref. \\
\hline $5.404(2)$ & $5.452(2)$ & $20.442(7)$ & Fmmm & 6.95 & {$[1]$} \\
\hline $5.407(4)$ & $5.454(4)$ & $20.54(2)$ & - & - & {$[6]$} \\
\hline $5.402(2)$ & $5.453(7)$ & $20.537(1)$ & - & - & [7] \\
\hline 5.412 & 5.456 & 20.94 & - & - & [9] \\
\hline 5.41 & 5.46 & 20.54 & - & - & [10] \\
\hline $5.3961(6)$ & $5.4498(5)$ & $20.522(2)$ & $\mathrm{Fmmm}$ & 6.92 & [11] \\
\hline $5.393(2)$ & $5.451(2)$ & $20.54(1)$ & Fmmm & 6.93 & [12] nitrate route \\
\hline $5.400(2)$ & $5.452(2)$ & $20.52(1)$ & $\mathrm{Fmmm}$ & 7.03 & [12] citrate route \\
\hline $5.3922(1)$ & $5.4488(1)$ & $20.5288(6)$ & $\mathrm{Fmmm}$ & 6.92 & [13] \\
\hline $5.3928(1)^{\star}$ & $5.4486(1)^{*}$ & $20.5185(5)^{\star}$ & Amam $^{*}$ & 7.02 & [14] \\
\hline $5.3971(2)^{*}$ & $5.4501(2)^{\star}$ & $20.507(1)^{*}$ & Amam $^{*}$ & 7.05 & [15] \\
\hline $20.502(1)^{*}$ & $5.4494(7)^{*}$ & $5.3981(7)^{\star}$ & $\mathrm{Cmcm}^{*}$ & - & {$[16]$} \\
\hline $5.409(2)$ & $5.452(2)$ & $20.537(3)$ & - & 6.72 & {$[17]$} \\
\hline
\end{tabular}

* neutron diffraction at $300 \mathrm{~K}$. Space groups Amam and $\mathrm{Cmcm}$ differ only by the setting of the crystallographic axes. 


\section{Experimental}

In order to prepare the $\mathrm{La}_{3} \mathrm{Ni}_{2-x} \mathrm{Fe}_{x} \mathrm{O}_{7 \pm \delta}$ $(x=0,0.05,0.10)$ powder samples for our study, stoichiometric amounts of $\mathrm{La}\left(\mathrm{NO}_{3}\right)_{3} \cdot 6 \mathrm{H}_{2} \mathrm{O}$ (chemical pure grade), $\mathrm{Ni}\left(\mathrm{CH}_{3} \mathrm{COO}\right)_{2} \cdot 4 \mathrm{H}_{2} \mathrm{O}$ (chemical pure grade), and of metallic iron were dissolved in an aqueous solution of nitric acid prepared from concentrated nitric acid (extra pure grade) and deionized water in the ratio 1:3 while heating and mixing on a hot plate. Metallic iron enriched in ${ }^{57} \mathrm{Fe}$ was obtained by reduction of $\mathrm{Fe}_{2} \mathrm{O}_{3}$ (with iron enriched by $96.6 \%$ in the isotope ${ }^{57} \mathrm{Fe}$ ) in flowing $\mathrm{H}_{2}$ at $925 \mathrm{~K}$ for 6 hours and then quantitatively transferred into solution. Subsequently, citric acid monohydrate $\mathrm{C}_{6} \mathrm{H}_{5} \mathrm{O}_{4}(\mathrm{OH})_{3} \cdot \mathrm{H}_{2} \mathrm{O}$ (chemical pure grade) was added to the solution as a chelating and gelling agent. The thus-prepared precursor solution was dried and decomposed forming a brown powder. The powder was calcined in air at $1273 \mathrm{~K}$ for 30 minutes to remove organic and carbon residuals and then cooled down to RT. The dark grey product was ground, pressed into pellets and annealed in air at $1373 \mathrm{~K}$ for $24 \mathrm{~h}$. In order to obtain single-phase $\mathrm{La}_{3} \mathrm{Ni}_{2-x} \mathrm{Fe}_{x} \mathrm{O}_{7 \pm \delta}$ materials $(x=0,0.05$, 0.10 ), 5-6 intermediate cycles of regrinding, pelletizing and annealing at $1373 \mathrm{~K}$ were required. Sample purity and morphology was checked by REM/EDX analysis (Jeol JSM-6510, Bruker Nano XFlash 410). The measurements confirmed the absence of any impurities and secondary phases in noticeable concentrations.

Phase composition and crystal structure of the synthesized samples were examined by powder X-ray diffraction using an Equinox 3000 diffractometer (INEL, France) with $\mathrm{Cu}$-Ka radiation $(\lambda=1.54178 \AA)$; data were collected in the asymmetric reflection mode. The scattered radiation from the flat-plate samples was registered by a curved position-sensitive detector (CPS-590) within the angle interval 10-90 in $2 \theta$. The detector was calibrated using $\mathrm{Na}_{2} \mathrm{Al}_{2} \mathrm{Ca}_{3} \mathrm{~F}_{14}$ as standard. The data acquisition time was $1 \mathrm{~h}$ for phase analysis and 17-21 h for structural analysis.

All calculations including the Rietveld refinements and determinations of crystal structure of samples studied were performed using the FullProf package [27]. The following structural parameters were varied in the refinement procedure: scale factor, unit cell parameters, zero shift, atomic positions, overall displacement parameters (B-factors, $B_{\text {ov }}$ ), background, peak shape, and width parameters. The peak profiles were described by the Thompson-Cox-Hasting pseudo-Voigt function within the anisotropic strain broadening model. The instrumental resolution function was determined by means of diffraction experiments with a $\mathrm{CeO}_{2}$ reference sample which had been annealed twice at $1473 \mathrm{~K}$ for $48 \mathrm{~h}$ with intermediate regrinding and then slowly cooled down to RT. The background was estimated by linear interpolation between manually selected background points with refinable heights.

Transmission ${ }^{57} \mathrm{Fe}$ Mössbauer spectra were taken using a standard Mössbauer system (Halder) in the sinusoidal driving mode employing a ${ }^{57} \mathrm{Co} / \mathrm{Rh} \gamma$-source with a maximum activity of $1.91 \mathrm{GBq}$. The relatively low iron content and high electronic mass-absorption coefficient of $\mathrm{La}_{3} \mathrm{Ni}_{2-x} \mathrm{Fe}_{x} \mathrm{O}_{7 \pm \delta}$ for the $14.4 \mathrm{keV}$ Mössbauer $\gamma$-radiation necessitated the use of samples enriched in ${ }^{57} \mathrm{Fe}$, see above. The least square fits of the spectra using lorentzian line shapes were performed by means of the Recoil Mössbauer data evaluation software [28] yielding the fol- 
lowing parameters: isomershift IS $\left(\mathrm{mm} \cdot \mathrm{s}^{-1}\right)$ relative to $\alpha-\mathrm{Fe}$ at RT, quadrupole splitting $Q S\left(\mathrm{~mm} \cdot \mathrm{s}^{-1}\right)$ of doublets, full width
$\Gamma\left(\mathrm{mm} \cdot \mathrm{s}^{-1}\right)$ at half maximum of lines, and (relative) spectral area $A(\%)$ of spectra.

\section{Mössbauer spectroscopy}

The RT ${ }^{57} \mathrm{Fe}$ Mössbauer spectra of $\mathrm{La}_{3} \mathrm{Ni}_{2-x} \mathrm{Fe}_{x} \mathrm{O}_{7 \pm \delta}(x=0.05,0.10)$ are displayed in Fig. 1.

The highly symmetric spectra are composed of two quadrupole-split doublets of almost identical intensity. This observation gives evidence of the fact that iron cations are incorporated on two inequivalent lattice sites which at present will be denoted by $A$ and $B$ for the site with the smaller and the larger quadrupole splitting $(Q S)$, respectively, $\mathrm{QS}\left(\mathrm{Fe}_{\mathrm{A}}\right)<\mathrm{QS}\left(\mathrm{Fe}_{\mathrm{B}}\right)$. The parameters obtained from the least square fits of the spectra are presented in Table 2.

The isomer shifts (IS) of $0.31 \mathrm{~mm} \cdot \mathrm{s}^{-1}$ of the two subspectra of $\mathrm{La}_{3} \mathrm{Ni}_{2-x} \mathrm{Fe}_{x} \mathrm{O}_{7 \pm \delta}$ are identical in the two solid solutions studied $(x=0.05$ and 0.10$)$. It is also to be noted that these values are in close agreement with the ${ }^{57} \mathrm{Fe}$ isomer shifts observed for the other octahedrally coordinated $\mathrm{La}_{n+1} \mathrm{Ni}_{n} \mathrm{O}_{3 n+1}$ R-P phases with $n=1$ and $n=3$ [21-26]. According to numerous Mössbauer studies, e. g. Refs. [29, 30], such IS-values are characteristic for high-spin $\mathrm{Fe}^{3+}$ ions octahedrally coordinated by oxygen.

The RT quadrupole splittings (QS) of the two doublets in $\mathrm{La}_{3} \mathrm{Ni}_{2-x} \mathrm{Fe}_{x} \mathrm{O}_{7 \pm \delta}$ are found to differ significantly with values of about $0.43 \mathrm{~mm} \cdot \mathrm{s}^{-1}$ and $0.95 \mathrm{~mm} \cdot \mathrm{s}^{-1}$ for iron incorporated on sites of type $A$ and $B$, respectively, Table 2. As also seen, Fig. 1, transmission can assume values as low as about $90 \%$ in parts of the spectra. Therefore, the absorbers used in the present study have to be characterized as "thick". This conclusion is also supported by the RT line widths of the two samples which take values ranging between 0.26 and $0.31 \mathrm{~mm} \cdot \mathrm{s}^{-1}$ and, thus, reveal significant broadening in comparison with the theoretical width of a ${ }^{57} \mathrm{Fe}$ Mössbauer line of about $0.20 \mathrm{~mm} \cdot \mathrm{s}^{-1}$ for "thin"

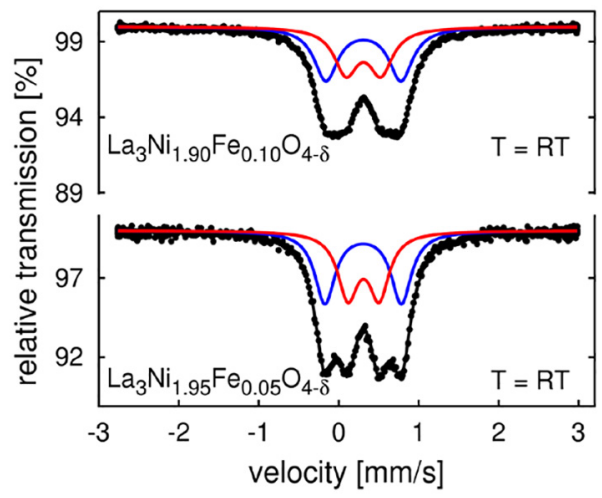

Fig. $1 .{ }^{57} \mathrm{Fe}$ Mössbauer spectra of $\mathrm{La}_{3} \mathrm{Ni}_{2-x} \mathrm{Fe}_{x} \mathrm{O}_{7 \pm \delta}(x=0.05$ and 0.10$)$ at RT

Table 2

Parameters of the $\mathrm{RT}^{57} \mathrm{Fe}$ Mössbauer spectra of $\mathrm{La}_{3} \mathrm{Ni}_{2-x} \mathrm{Fe}_{x} \mathrm{O}_{7 \pm \delta}(x=0.05$ and 0.10$)$ : $I S$ - isomer shift (vs $\alpha-\mathrm{Fe}$ ), $Q S-$ quadrupolar splitting, $\Gamma-$ full line width at half maximum (FWHM), $A$ - experimental area fraction

\begin{tabular}{c|c|c|c|c|c}
\hline Compound & $I S\left(\mathrm{~mm} \cdot \mathrm{s}^{-1}\right)$ & $Q S\left(\mathrm{~mm} \cdot \mathrm{s}^{-1}\right)$ & $\Gamma\left(\mathrm{mm} \cdot \mathrm{s}^{-1}\right)$ & $A(\%)$ & site \\
\hline $\mathrm{La}_{3} \mathrm{Ni}_{1.95} \mathrm{Fe}_{0.05} \mathrm{O}_{7 \pm \delta}$ & 0.31 & 0.41 & 0.30 & 50 & $\mathrm{~A}$ \\
\hline & 0.31 & 0.97 & 0.26 & 50 & $\mathrm{~B}$ \\
\hline $\mathrm{La}_{3} \mathrm{Ni}_{1.90} \mathrm{Fe}_{0.10} \mathrm{O}_{7 \pm \delta}$ & 0.31 & 0.46 & 0.31 & 47 & $\mathrm{~A}$ \\
\hline & 0.31 & 0.93 & 0.28 & 53 & $\mathrm{~B}$
\end{tabular}


absorbers. In addition to line broadening, the thickness effect can also give rise to intensity distortion in the spectra as will be discussed below.

Predominantly, low transmission and broadening of the experimental Mössbauer lines can be attributed to the substitution of nickel by iron strongly enriched in ${ }^{57} \mathrm{Fe}$ (96.6\%) which causes large values for the total absorber thickness $t_{\mathrm{a}}$ of the samples. In the present case with ${ }^{57} \mathrm{Fe}$ on two sites of the structure, $t_{\mathrm{a}}$ it is defined as $t_{\mathrm{a}}=$ $\left(f_{\mathrm{A}} N_{\mathrm{A}}+f_{\mathrm{B}} N_{\mathrm{B}}\right) \cdot \sigma_{0}$ [31]. Here, $f_{\varepsilon}$ represents the Debye-Waller factor of atoms of type $\varepsilon(\varepsilon=\mathrm{A}, \mathrm{B})$ and $N_{\varepsilon}$ their number per $\mathrm{cm}^{2}$ of absorber; $\sigma_{0}=2.56 \cdot 10^{-18} \mathrm{~cm}^{2}$ is the absorption cross section of a Mössbauer atom. In the present work, an estimate of 0.75 can be assumed for the RT DebyeWaller factor. Using this approximate value, estimates of about $t_{\mathrm{a}}=4.0$ and 8.0 are obtained for total absorber thicknesses of the $\mathrm{La}_{3} \mathrm{Ni}_{2-x} \mathrm{Fe}_{x} \mathrm{O}_{7 \pm \delta}$ samples with $x=0.05$ and 0.10 , respectively, Fig. 1.

For non-overlapping doublets of lorentzian shape, these $t_{\mathrm{a}}$-values would give rise to theoretical line widths of about $0.23 \mathrm{~mm} \cdot \mathrm{s}^{-1}$ and $0.25 \mathrm{~mm} \cdot \mathrm{s}^{-1}$ for $x=0.05$ and 0.10 , respectively, see e.g. Refs. [29, 31]. However, as seen, Fig.1, doublets are overlapping to various degree. Notably the inner doublet $\mathrm{A}$ is almost fully overlapped by doublet B. In the limit of full overlap, theoretical line widths amount to about $0.25 \mathrm{~mm} \cdot \mathrm{s}^{-1}$ and $0.30 \mathrm{~mm} \cdot \mathrm{s}^{-1}$ for $x=0.05$ and $x=0.1$, respectively $[29,31]$. Indeed, in agreement with these expectations, line widths observed for the inner doublet, A, are always larger than those of doublet B, Table 2. Remaining discrepancies between theoretical and experimental line widths can easily be attributed to the fact that quadrupolar interactions of the iron nuclei possess a distribution, see below, which provides an additional source for line broadening. As a further consequence of the present large values of total absorber thickness $t_{\mathrm{a}}$, spectra undergo intensity distortion which always causes an underestimation of large spectral contributions on the basis of experimental signal areas. As has been demonstrated by Rancourt [31], such intensity corrections can be very large. In the present case, however, they are almost nonexistent $(x=$ $0.05)$ or very moderate $(\sim 2 \%$ for $x=0.10)$ due to the (almost) equal areas of the two experimental doublets. Thus, in the present case corrections to experimental signal intensities can well be neglected.

\section{Crystal structure}

As discussed in the Introduction, to date the crystal structure of $\mathrm{La}_{3} \mathrm{Ni}_{2} \mathrm{O}_{7 \pm \delta}$ has been assigned to the orthorhombic space groups Fmmm (№ 69) $[1,11-13]$ or $\mathrm{Cmcm}$ (№ 63) [14, 15]. According to these structural models, lanthanum cations occupy two different crystallographic positions, but the nickel cations are located on a single site exclusively. This is in striking contrast with the present results of the Mössbauer measurements which clearly indicate the existence of two nonequivalent lat-

tice sites for iron/nickel in the studied $\mathrm{La}_{3} \mathrm{Ni}_{2-x} \mathrm{Fe}_{x} \mathrm{O}_{7 \pm \delta}$ solid solutions at $\mathrm{RT}$. In order to explain the unexpected observations made in Mössbauer spectroscopy for the $n=2$ member of the R-P series, in the following an attempt will be undertaken to search for adequate structural models of $\mathrm{La}_{3} \mathrm{Ni}_{2-x} \mathrm{Fe}_{x} \mathrm{O}_{7 \pm \delta}(x \geq 0)$ accounting for two inequivalent $\mathrm{Ni} / \mathrm{Fe}$ sites.

The XRD patterns of the synthesized $\mathrm{La}_{3} \mathrm{Ni}_{2-x} \mathrm{Fe}_{x} \mathrm{O}_{7 \pm \delta}(x=0,0.05,0.10)$ powder samples were indexed in orthorhom- 
bic symmetry. Unit cell parameters $a=$ $20.52298 \AA, b=5.45805 \AA, c=5.40101 \AA$, $\left(\alpha=\beta=\gamma=90^{\circ}\right)$ of $\mathrm{La}_{3} \mathrm{Ni}_{1.9} \mathrm{Fe}_{0.1} \mathrm{O}_{7 \pm \delta}$ were obtained with the help of the DICVOL04 program [32] and the figures of merit provided by this analysis amounted to $\mathrm{M}(20)$ $=56.2, \mathrm{~F}(20)=60.7$. Calculations by means of the ITO program [33] resulted in a preferable face-centered space group with almost the same unit cell parameters of $a=$ 5.4577 $\AA$, $b=20.5225 \AA$, and $c=5.4020(\alpha=$ $\left.\beta=\gamma=90^{\circ}\right)$, and a figure of merit $\mathrm{F}(20)=$ 59.3. After preliminary profile-matching refinement within primitive orthorhombic Pmmm, probable space groups were searched for by means of the CheckGroup program interfaced by WinPlotr [34]. Thus, 48 possible space groups were obtained for consideration. Most of them are primitive with quite low values for figures of merit $(<1.35)$. In order to reduce the number of space groups, we focused on those which can be deduced from group-subgroup relations keeping both unit cell dimensions and orthorhombic crystal system of the parent group unchanged. Referring to International Tables for Crystallography [35] only 6 subgroups remained: $C c c a$ (No 68), Cmma (No 67), Cccm (No 66), Cmmm (No 65), Cmca (No 64), and $\mathrm{Cmcm}$ (No 63). Bearing in mind the results of Mössbauer spectroscopy that reveal the existence of two nonequivalent sites for iron/nickel ions, the list of possible space groups shortens to three: $\mathrm{Cmmm}$ (No 65), Cmma (No 67), and Bmmb (non-standard setting of $\mathrm{Cmcm}$ space group) (No 63).

The next step of our study was an attempt to determine the crystal structure of $\mathrm{La}_{3} \mathrm{Ni}_{1.9} \mathrm{Fe}_{0.1} \mathrm{O}_{7 \pm \delta}$ from XRD patterns by constructing the Patterson maps using observed structure amplitudes and the peak search procedure of the GFourier program [34]. The Patterson maps were constructed from the structural amplitudes extracted during the profile-matching fit according to the Le Bail algorithm for each chosen space group.

Note that the simplest crystal structure solutions should be expected for both Fmmm and Cmmm models because these space groups correspond to exactly the same Patterson space groups Fmmm and Cmmm [35]. This means that one has exactly the same symmetry both in real space and Patterson space. As far as for $\mathrm{X}$-ray diffraction, both nickel and iron atoms are indistinguishable and, thus, $\mathrm{La}_{3} \mathrm{Ni}_{1.9} \mathrm{Fe}_{0.1} \mathrm{O}_{7 \pm \delta}$ contains three types of atoms with substantially different numbers of electrons. Consequently, the observed peaks on the Patterson map might be resolved except for those having the same interatomic distances, for example the La1Lal and Ni-Ni bond lengths in the perovskite layers of the Fmmm structure. Additionally, if the heaviest atom (La) is placed into the origin of the unit cell with coordinates $(0,0,0)$ - as we did in the present case - then the peaks observed in Patterson space relate to interatomic vectors with coordinates $(u= \pm\{x-0\}, v= \pm\{y-0\}, w=$ $\pm\{z-0\})$ and coincide with atomic positions $( \pm x, \pm y, \pm z)$ in real space. Accounting for these considerations, we were able to solve the crystal structure for $\mathrm{La}_{3} \mathrm{Ni}_{1.9} \mathrm{Fe}_{0.1} \mathrm{O}_{7 \pm \delta}$ in the framework of Fmmm and $\mathrm{Cmmm}$ space groups directly from the peaks observed in Patterson maps. The results of the crystal structure solutions for $\mathrm{La}_{3} \mathrm{Ni}_{1.9} \mathrm{Fe}_{0.1} \mathrm{O}_{7 \pm \delta}$, which are summarized in Table 3, confirm our above mentioned expectations.

As can be seen from Table 3, only a single crystallographic position is available for nickel/iron cations within the $\mathrm{Fmmm}$ crystal structure of $\mathrm{La}_{3} \mathrm{Ni}_{1.9} \mathrm{Fe}_{0.1} \mathrm{O}_{7 \pm \delta}$. This is in agreement with the earlier pro- 
Table 3

Crystal structure solutions for $\mathrm{La}_{3} \mathrm{Ni}_{1.9} \mathrm{Fe}_{0.1} \mathrm{O}_{7 \pm \delta}$ according to Fmmm and Cmmm models obtained from Patterson maps using peak search procedure of GFourier program [34]

\begin{tabular}{c|c|c|c|c|c|c}
\hline \multirow{2}{*}{$\begin{array}{c}\text { Peak } \\
\text { No }\end{array}$} & \multicolumn{2}{|c|}{ Relative atomic coordinates } & \multirow{2}{*}{ Occupation } & $\begin{array}{c}\text { Peak } \\
\text { height }\end{array}$ & $\begin{array}{c}\text { Wyckoff } \\
\text { position }\end{array}$ & $\begin{array}{c}\text { Type } \\
\text { of atom }\end{array}$ \\
\cline { 2 - 3 }
\end{tabular}

Fmmm (69): $a=5.4020 \AA, b=5.4570 \AA, c=20.5170 \AA$

general multiplicity 32

\begin{tabular}{c|c|c|c|c|c|c|c}
\hline 1 & 0 & 0 & 0 & 0.125 & 9872 & $4 a$ & La1 \\
\hline 2 & 0 & 0 & 0.1837 & 0.25 & 6488 & $8 i$ & La2 \\
\hline 3 & 0 & 0 & 0.4067 & 0.25 & 4024 & $8 i$ & Ni \\
\hline 4 & 0 & 0 & 0.5 & 0.125 & 1293 & $4 b$ & O1 \\
\hline 5 & 0 & 0 & 0.3076 & 0.25 & 1238 & $8 i$ & O2 \\
\hline 6 & 0.25 & 0.25 & 0.0922 & 0.5 & 1067 & $16 j$ & O3 \\
\hline
\end{tabular}

Cmmm (65): $a=5.4014 \AA, b=5.4576 \AA$, $c=20.5182 \AA$

general multiplicity 16

\begin{tabular}{c|c|c|c|c|c|c|c}
\hline 1 & 0 & 0 & 0 & 0.125 & 9892 & $2 a$ & La1 \\
\hline 2 & 0 & 0.5 & 0.5 & 0.125 & 8427 & $2 c$ & La2 \\
\hline 3 & 0 & 0.5 & 0.3158 & 0.25 & 6163 & $4 l$ & La4 \\
\hline 4 & 0 & 0 & 0.1830 & 0.25 & 5778 & $4 k$ & La3 \\
\hline 5 & 0 & 0.5 & 0.0907 & 0.25 & 3864 & $4 l$ & Ni2 \\
\hline 6 & 0 & 0 & 0.4035 & 0.25 & 3855 & $4 k$ & Ni1 \\
\hline 7 & 0 & 0.5 & 0.1990 & 0.25 & 1105 & $4 l$ & O4 \\
\hline 8 & 0.25 & 0.25 & 0.0925 & 0.5 & 1028 & $8 m$ & O6 \\
\hline 9 & 0.25 & 0.25 & 0.4030 & 0.5 & 992 & $8 m$ & O5 \\
\hline 10 & 0 & 0.5 & 0 & 0.125 & 937 & $2 b$ & O1 \\
\hline 11 & 0 & 0 & $0.4922^{*}$ & $0.25^{\star}$ & 987 & $4 l^{\star}$ & O2 \\
\hline 12 & 0 & 0 & 0.2992 & 0.125 & 881 & $4 k$ & O3
\end{tabular}

* here $Z$ should be 0.5 , the occupancy equal to 0.125 and the Wyckoff position should be $2 d$ according to the chemical composition $\mathrm{La}_{3} \mathrm{Ni}_{1.9} \mathrm{Fe}_{0.1} \mathrm{O}_{7}$

posed $\mathrm{Fmmm}$ space group for undoped $\mathrm{La}_{3} \mathrm{Ni}_{2} \mathrm{O}_{6.92}$ by Zhang et al. [11]. The main difference is that we place lanthanum into position (4a) at the origin of the unit cell $(0,0,0)$. Zhang puts one of the oxygen anions in that position (4a) and the lanthanum cations in position $4 \mathrm{~b}$ with relative coordinates $(0,0,0.5)$. In contrast, the $\mathrm{Cmmm}$ space group possesses two different crystallographic sites (4k and 4l) for nickel cations. Thus, the $\mathrm{Cmmm}$ model can provide an explanation for the observed RT
Mössbauer spectra of the $\mathrm{La}_{3} \mathrm{Ni}_{2-x} \mathrm{Fe}_{x} \mathrm{O}_{7 \pm \delta}$ solid solutions $(x=0.05,0.1)$.

In addition, it is worth noting that the space groups under consideration are subgroups of the space group Fmmm. Thus, if the Wyckoff positions of each atom in $F m m m$ are known, we can easily deduce the Wyckoff positions of each atom in the corresponding subgroup. The transformation of atomic coordinates from Fmmm (Table 3) to the corresponding subgroups was performed by the Pow- 
derCell program [36] in order to reveal the possibility for the appearance of nonequivalent positions for nickel cations. As a result, of the six subgroups considered, only three would meet the latter criterion, namely Cmma (№ 67), Cmmm (№ 65), and $B m m b$ (№ 63) - a non-standard setting of the $\mathrm{Cmcm}$ space group.

The Rietveld analysis of XRD patterns for $\mathrm{La}_{3} \mathrm{Ni}_{2-x} \mathrm{Fe}_{x} \mathrm{O}_{7 \pm \delta}$ within the suggested crystal structure models as well as thorough search for additional reflections with even tiny intensities which could definitely be attributed to a particular space group did not allow us to arrive at a final conclusion. As an example, Fig. 2 illustrates the refined Rietveld powder profiles of $\mathrm{La}_{3} \mathrm{Ni}_{2-x} \mathrm{Fe}_{x} \mathrm{O}_{7 \pm \delta}$ solid solutions within space groups $\mathrm{Cmmm}$ (A), Cmma (B), and $B m m b$ (C). Table 4 summarizes $R$-factors and chi-square values $\left(\chi^{2}\right)$ for all refined patterns in the framework of the proposed structural models with two inequivalent sites for $\mathrm{Ni} / \mathrm{Fe}$ - space group Fmmm which provides only a single site for $\mathrm{Ni} / \mathrm{Fe}$ is included for comparison. On the basis of these R-factor and $\chi^{2}$ data, the following observations can be made: (i) Fmmm appears the least probable space group, (ii) fits within $\mathrm{Cmmm}$ and $\mathrm{Cmma}$ appear slightly superior to $\mathrm{Bmmb}$, (iii) no significant differences can be observed between $\mathrm{Cmmm}$ and Cmma. Therefore, no valid conclusion can be drawn in respect to the true space group of $\mathrm{La}_{3} \mathrm{Ni}_{2-x} \mathrm{Fe}_{x} \mathrm{O}_{7 \pm \delta}$ on the basis of the present $\mathrm{X}$-ray diffraction data.

Table 5 and Table 6 report the results of the Rietveld refinements for $\mathrm{La}_{3} \mathrm{Ni}_{2-x} \mathrm{Fe}_{x} \mathrm{O}_{7 \pm \delta}$ in the two most probable space groups Cmma and $\mathrm{Cmmm}$, respectively. The crystal structures of $\mathrm{La}_{3} \mathrm{Ni}_{2-x} \mathrm{Fe}_{x} \mathrm{O}_{7 \pm \delta}$ $(x=0,0.05,0.10)$ solid solutions confined to space groups Cmmm, Cmma, and $\mathrm{Bmmb}$ with two inequivalent sites (Ni1 and Ni2) for Ni/Fe are shown in Fig. 3. For reason of comparison, the graph also shows the structural model for space group Fmmm. As can be seen from Fig. 3, in all cases the lattice is built up from double perovskite layers $2\left[\mathrm{La}(\mathrm{Ni} / \mathrm{Fe}) \mathrm{O}_{3}\right]$ which are stacked between single rock-salt $\mathrm{LaO}$ layers along the $c$-axis. In $\mathrm{Cmmm}$, Cmma, and $B m m b$, the double perovskite layers consist of two different $\mathrm{Ni} / \mathrm{FeO}_{6}$ octahedra (Ni1, Ni2) with slightly different distortions. Within the double perovskite layers the differently distorted octahedral Ni/Fe sites are arranged in different ways, Fig. 3B-D.
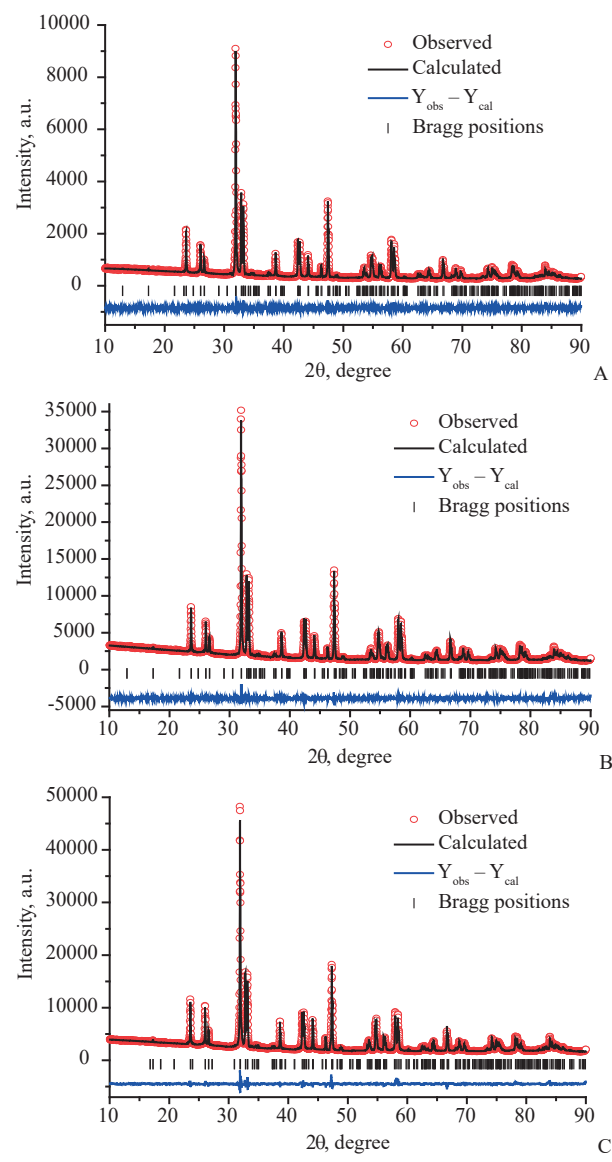

Fig. 2. Rietveld refined XRD powder patterns of $\mathrm{La}_{3} \mathrm{Ni}_{2-x} \mathrm{Fe}_{x} \mathrm{O}_{7 \pm \delta}$ solid solutions within space groups $\mathrm{Cmmm}$ for $x=0$ (A), Cmma for $x=0.05(\mathrm{~B})$, and $B m m b$ for $x=0.10(\mathrm{C})$ 
Finally, $a$ - and $b$-parameters and the unit cell volume $V$ of the $\mathrm{La}_{3} \mathrm{Ni}_{2-x} \mathrm{Fe}_{x} \mathrm{O}_{7 \pm \delta}$ solid solutions are found to increase with Fe content $(x)$, (see Tables 5 and Table 6) which are in good agreement with size factor for $3 d$-metal cations: $r\left(\mathrm{Fe}^{3+}\right)=79 \mathrm{pm}>r\left(\mathrm{Ni}^{3+}\right)$ $=74 \mathrm{pm}[37]$.

Comparison of $R$-factors and $\chi^{2}$-values obtained for structural models

Table 4 of $\mathrm{La}_{3} \mathrm{Ni}_{2-x} \mathrm{Fe}_{x} \mathrm{O}_{7 \pm \delta}$ solid solutions after Rietveld refinement

\begin{tabular}{c|c|c|c|c|c}
\hline Iron content & Space group & $R_{\mathrm{p}}$ & $R_{w p}$ & $R_{\text {exp }}$ & $\chi^{2}$ \\
\hline \multirow{5}{*}{$x=0$} & $F m m m$ & 4.65 & 6.02 & 4.56 & 1.74 \\
\cline { 2 - 6 } & $C m m a$ & 4.38 & 5.71 & 4.59 & 1.55 \\
\cline { 2 - 6 } & $C m m m$ & 4.36 & 5.69 & 4.58 & 1.54 \\
\cline { 2 - 6 } & $B m m b$ & 4.51 & 5.86 & 4.58 & 1.64 \\
\hline \multirow{5}{*}{$x=0.05$} & $F m m m$ & 2.85 & 3.89 & 2.19 & 3.16 \\
\cline { 2 - 6 } & $C m m a$ & 2.55 & 3.51 & 2.17 & 2.62 \\
\cline { 2 - 6 } & $C m m m$ & 2.56 & 3.54 & 2.17 & 2.68 \\
\cline { 2 - 6 } & $B m m b$ & 2.64 & 3.66 & 2.18 & 2.83 \\
\hline \multirow{5}{*}{$x=0.1$} & $F m m m$ & 2.95 & 4.17 & 1.90 & 4.82 \\
\cline { 2 - 6 } & $C m m a$ & 2.84 & 3.99 & 1.89 & 4.46 \\
\cline { 2 - 6 } & $C m m m$ & 2.96 & 4.15 & 1.91 & 4.72 \\
\cline { 2 - 6 } & $B m m b$ & 2.82 & 4.03 & 1.89 & 4.53
\end{tabular}

Table 5

Rietveld refined atomic coordinates and bond lengths $L(\mathrm{Ni}-\mathrm{O})$ for $\mathrm{La}_{3} \mathrm{Ni}_{2-x} \mathrm{Fe}_{x} \mathrm{O}_{7}(x=0,0.05$,

0.10) solid solutions within the Cmma model: $4 g$ : La1 - $(0,0.25,0.25), \mathrm{O} 3-(0,0.25,0.75)$, $\mathrm{La} 2,3 / \mathrm{Ni} 1,2 / \mathrm{O} 1,2-(0,0.25, Z) ; 81: \mathrm{O} 4,5-(0.25,0, Z), \mathrm{RT}$

\begin{tabular}{c|c|c|c}
\hline Refined parameter & $x=0$ & $x=0.05$ & $x=0.10$ \\
\hline zero point & $0.025(1)$ & $-0.0044(8)$ & $0.0038(8)$ \\
\hline$B_{\text {ov }} \AA^{2}$ & $1.66(4)$ & $1.50(3)$ & $1.58(3)$ \\
\hline$a, \AA$ & $5.3895(1)$ & $5.3970(1)$ & $5.4019(1)$ \\
\hline$b, \AA$ & $5.4462(1)$ & $5.4521(1)$ & $5.4574(1)$ \\
\hline$c, \AA$ & $20.5250(3)$ & $20.5280(2)$ & $20.5192(2)$ \\
\hline$V, \AA^{3}$ & $602.46(1)$ & $604.04(1)$ & $604.91(1)$ \\
\hline$Z(\mathrm{La} 2)$ & 0.06994 & 0.06994 & 0.07007 \\
\hline$Z(\mathrm{La} 3)$ & 0.43006 & 0.43006 & 0.42993 \\
\hline$Z(\mathrm{Ni} 1)$ & $0.8476(2)$ & $0.8472(1)$ & $0.8469(1)$ \\
\hline$Z(\mathrm{Ni2})$ & $0.6524(2)$ & $0.6528(1)$ & $0.6531(1)$ \\
\hline$Z(\mathrm{O} 1)$ & $0.9526(6)$ & $0.9454(7)$ & 0.94918 \\
\hline$Z(\mathrm{O} 2)$ & $0.5474(6)$ & 0.54719 & 0.55082 \\
\hline$Z(\mathrm{O} 4)$ & $0.6448(9)$ & $0.6415(5)$ & $0.6439(6)$ \\
\hline
\end{tabular}


Continuation of table 5

\begin{tabular}{c|c|c|c}
\hline Refined parameter & $x=0$ & $x=0.05$ & $x=0.10$ \\
\hline$Z(\mathrm{O} 5)$ & $0.838(1)$ & $0.8370(7)$ & $0.8389(8)$ \\
\hline$L(\mathrm{Ni1}-\mathrm{O} 3), \AA$ & $2.003(4)$ & $1.995(2)$ & $1.988(3)$ \\
\hline$L(\mathrm{Ni} 1 / \mathrm{Ni2}-\mathrm{O} 1 / \mathrm{O} 2), \AA$ & $2.16(1)$ & $2.01(1)$ & $2.099(3)$ \\
\hline $4 L(\mathrm{Ni1}-\mathrm{O} 5), \AA$ & $1.926(2)$ & $1.929(2)$ & $1.927(2)$ \\
\hline Average $L(\mathrm{Ni1}-\mathrm{O}), \AA$ & $1.977(2)$ & $1.954(3)$ & $1.9657(8)$ \\
\hline$L(\mathrm{Ni2}-\mathrm{O} 3), \AA$ & $2.003(4)$ & $2.169(2)$ & $1.988(3)$ \\
\hline $4 L(\mathrm{Ni} 2-\mathrm{O} 4), \AA$ & $1.922(2)$ & $1.932(1)$ & $1.929(2)$ \\
\hline Average $L(\mathrm{Ni2}-\mathrm{O}), \AA$ & $1.974(2)$ & $1.9818(7)$ & $1.967(5)$
\end{tabular}

Table 6

Rietveld refined relative atomic coordinates and bond-lengths $L(\mathrm{Ni}-\mathrm{O})$ for $\mathrm{La}_{3} \mathrm{Ni}_{2-x} \mathrm{Fe}_{x} \mathrm{O}_{7}(x=0$, $0.05,0.10)$ solid solutions within the Cmmm model: $2 a$ : La1 $-(0,0,0), 2 b$ : O1 $-(0,0.5,0) 2 c$ : $\mathrm{La} 2-(0,0.5,0.5), 2 d: \mathrm{O} 2-(0,0,0.5), 4 k: \mathrm{La} 3 / \mathrm{Ni} 1 / \mathrm{O} 3-(0,0, \mathrm{Z}), 4 l: \mathrm{La} 4 / \mathrm{Ni} 2 / \mathrm{O} 4-(0,0.5, \mathrm{Z})$, $8 m: \mathrm{O} 5 / \mathrm{O} 6-(0.25,0.25, \mathrm{Z}), \mathrm{RT}$

\begin{tabular}{|c|c|c|c|}
\hline Refined parameter & $x=0$ & $x=0.05$ & $x=0.10$ \\
\hline zero point & $0.025(1)$ & $-0.0043(8)$ & $0.0038(8)$ \\
\hline$B_{\mathrm{ov}} \AA^{2}$ & $1.66(4)$ & $1.47(3)$ & $1.61(3)$ \\
\hline$a, \AA$ & $5.3895(1)$ & $5.3971(1)$ & $5.4019(1)$ \\
\hline$b, \AA$ & $5.4462(1)$ & $5.4521(1)$ & $5.4574(1)$ \\
\hline$c, \AA$ & $20.5250(3)$ & $20.5279(2)$ & $20.5191(2)$ \\
\hline$V, \AA^{3}$ & $602.46(1)$ & $604.044(8)$ & $604.91(1)$ \\
\hline$Z(\mathrm{La} 3)$ & 0.18006 & 0.18016 & 0.17993 \\
\hline$Z(\mathrm{La} 4)$ & 0.31994 & 0.31984 & 0.32007 \\
\hline$Z(\mathrm{Ni1})$ & $0.4024(2)$ & $0.4029(1)$ & $0.4031(1)$ \\
\hline$Z(\mathrm{Ni} 2)$ & $0.0976(2)$ & $0.0971(1)$ & $0.0969(1)$ \\
\hline$Z(\mathrm{O} 3)$ & $0.298(1)$ & 0.30079 & $0.2952(9)$ \\
\hline$Z(\mathrm{O} 4)$ & 0.20267 & $0.2049(8)$ & 0.19918 \\
\hline$Z(\mathrm{O} 5)$ & $0.3943(9)$ & $0.4016(3)$ & $0.4021(4)$ \\
\hline$Z(\mathrm{O} 6)$ & $0.087(1)$ & $0.0984(3)$ & $0.0979(4)$ \\
\hline$L(\mathrm{Ni1} / \mathrm{Ni2}-\mathrm{O} 2 / \mathrm{O} 1), \AA$ & $2.003(4)$ & $1.994(2)$ & $1.989(3)$ \\
\hline$L(\mathrm{Ni1}-\mathrm{O} 3), \AA$ & $2.15(3)$ & $2.095(2)$ & $2.21(2)$ \\
\hline $4 L(\mathrm{Ni1} / \mathrm{Ni} 2-\mathrm{O} 5 / \mathrm{O} 6), \AA$ & $1.923(2)$ & $1.9181(1)$ & $1.9198(1)$ \\
\hline Average $L(\mathrm{Ni1}-\mathrm{O}), \AA$ & $1.974(4)$ & $1.9603(5)$ & $1.980(3)$ \\
\hline$L(\mathrm{Ni} 2-\mathrm{O} 4), \AA$ & $2.157(4)$ & $2.21(2)$ & $2.099(3)$ \\
\hline Average $L(\mathrm{Ni} 2-\mathrm{O}), \AA$ & $1.979(1)$ & $1.980(3)$ & $1.944(4)$ \\
\hline
\end{tabular}



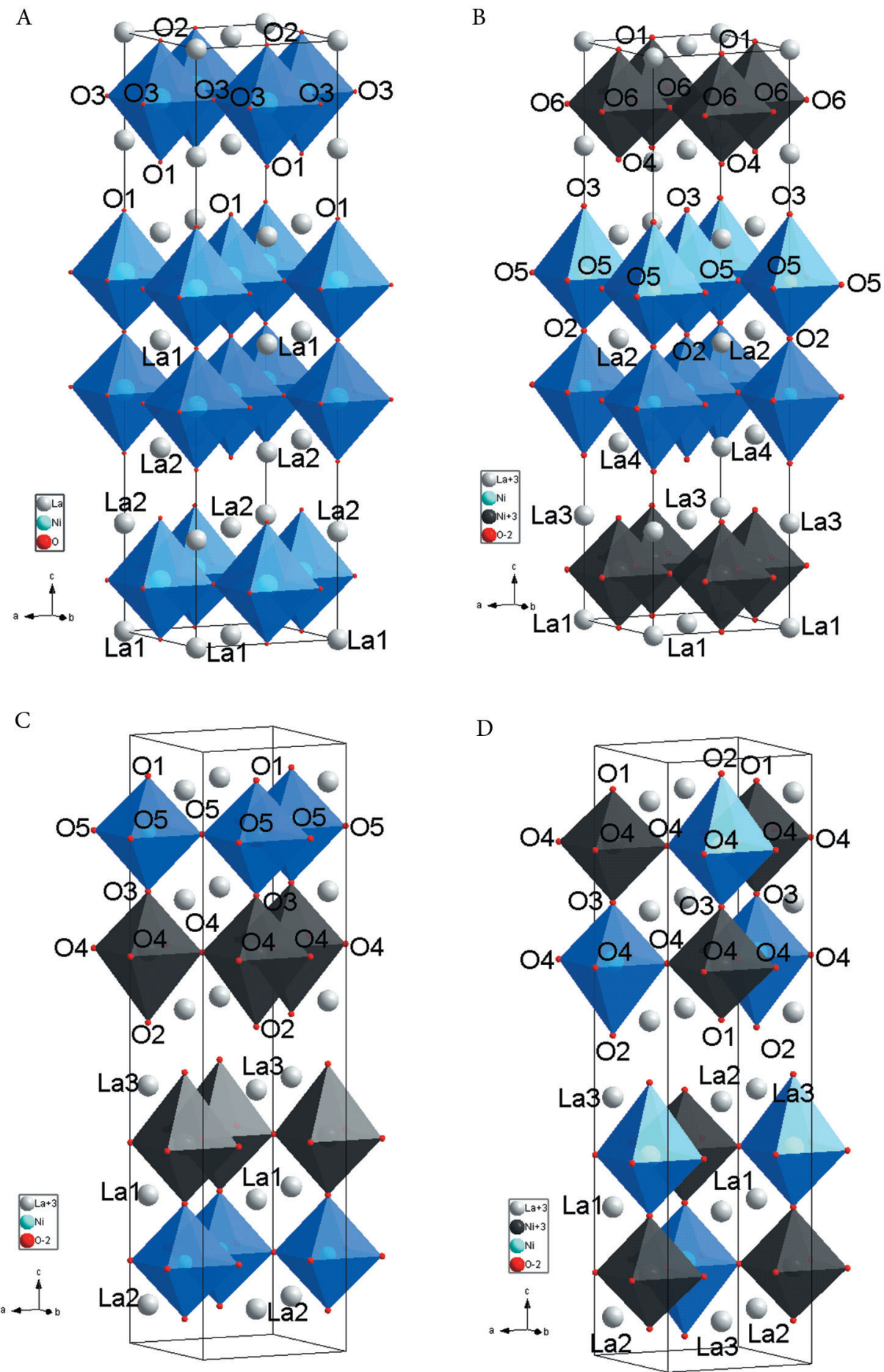

Fig. 3. Crystal structures of $\mathrm{La}_{3} \mathrm{Ni}_{2-x} \mathrm{Fe}_{x} \mathrm{O}_{7}$ solid solutions within space groups $F m m m(\mathrm{~A})$, $\mathrm{Cmmm}$ (B), Cmma (C), and Bmmb (D): grey balls $-\mathrm{La}^{3+}$, blue and dark grey octahedra represent oxygen environments of nickel/iron cations on Ni1- and Ni2-sites, respectively 


\section{Discussion}

The RT Mössbauer spectra of $\mathrm{La}_{3} \mathrm{Ni}_{2-x} \mathrm{Fe}_{x} \mathrm{O}_{7 \pm \delta}$ reveal that the sites for iron are characterized by two significantly different quadrupolar interactions, Table 2. In general, the ${ }^{57} \mathrm{Fe}$ Mössbauer quadrupole splitting is given by [29]

$$
Q S=\frac{1}{2} e Q V_{z z} \sqrt{1+\frac{1}{3} \eta^{2}}
$$

where the so-called asymmetry parameter $\eta$ is defined as $\eta=\left(V_{x x}-V_{y y}\right) / V_{z z}(0 \leq \eta$ $\leq 1)$ and where $V_{\alpha a}(\alpha=x, y, z)$ represent the electric field gradients (EFGs) at the nucleus in the principal axis system with $\left|V_{z z}\right|$ $\geq\left|V_{y y}\right| \geq\left|V_{x x}\right|$. Q denotes the quadrupole moment of the first excited nuclear state of ${ }^{57} \mathrm{Fe}$ and $e$ is the proton charge. In the case of $\mathrm{Fe}^{3+}$ ions possessing the $\mathrm{d}^{5}$ electronic configuration it is reasonable to assume that the experimental quadrupole splittings are dominated by the so-called lattice contribution to the electric field gradient which is determined by the positions and charges of the ions surrounding the Mössbauer atoms in the lattice. According to Eq. (1), the quadrupole interaction is sensitive to local symmetry around the nuclear probes in that $\eta=0$ for local tetragonal symmetry and that the interaction vanishes for local cubic symmetry, $V_{z z}=0$. Thus, the splittings reflect an asymmetry of the charge distribution in the crystal lattice around the nuclear probes and notably also the local distortion of their coordination polyhedra.

The RT Mössbauer data clearly reveal that the two sites, A and B, occupied by iron differ significantly in respect to the quadrupolar interactions experienced by the probe nuclei, $Q S\left(\mathrm{Fe}_{\mathrm{A}}\right)<Q S\left(\mathrm{Fe}_{\mathrm{B}}\right)$, Table 2. Under the assumption that iron substitutes for nickel, this experimental finding is in conflict with the structural assignments made to date for $\mathrm{La}_{3} \mathrm{Ni}_{2} \mathrm{O}_{7 \pm \delta}$, i. e. space groups Fmmm [1, 11-13], Amam [14], and Cmcm [15], which provide only one unique site for $\mathrm{Ni} / \mathrm{Fe}$ in the structure. The assumption made here that iron adopts nickel sites is strongly supported by successful predictions made in respect to the neighboring R-P phases $\mathrm{La}_{2} \mathrm{Ni}_{1-x} \mathrm{Fe}_{x} \mathrm{O}_{4+\delta}[21-24]$ and $\mathrm{La}_{4} \mathrm{Ni}_{3-x} \mathrm{Fe}_{x} \mathrm{O}_{10-\delta}[24,26]$. Their ${ }^{57} \mathrm{Fe}$ Mössbauer spectra are composed - as predicted on the basis of their layered R-P structures - of one and of two doublets, respectively. Further on, this assumption is also supported by crystal chemical arguments for the transition metal cations which make high-spin $\mathrm{Fe}^{3+}$ ions with their intermediate ionic radius of $79 \mathrm{pm}$ a perfect substitute for both high-spin $\mathrm{Ni}^{3+}(74 \mathrm{pm})$ and $\mathrm{Ni}^{2+}(83 \mathrm{pm})$ cations [37]. Thus, provided that iron substitutes for nickel and that one of the aforementioned space groups applies, only one signal is expected in the Mössbauer spectrum of $\mathrm{La}_{3} \mathrm{Ni}_{2-x} \mathrm{Fe}_{x} \mathrm{O}_{7 \pm \delta}(x>0)$ which is in contrast with experiment.

Two possible explanations can be offered for this unexpected observation of two nonequivalent sites for $\mathrm{Fe} / \mathrm{Ni}$. The first would be the conjecture that the $\mathrm{La}_{3} \mathrm{Ni}_{2-x} \mathrm{Fe}_{x} \mathrm{O}_{7 \pm \delta}$ solid solutions at RT adopt a lower symmetry than hitherto assumed. This approach has been followed in Crystal structure section, where possible structural models have been indicated. The second explanation, which will be discussed below, involves a local reconstruction of the R-P layer structure.

Indeed, a low-symmetry phase at RT cannot be unexpected in view of the fact that the mixed-valent $\mathrm{La}_{3} \mathrm{Ni}_{2-x} \mathrm{Fe}_{x} \mathrm{O}_{7 \pm \delta}$ contains $\mathrm{Ni}^{3+}$ and $\mathrm{Ni}^{2+}$ cations in similar concentrations 


$$
\left[\mathrm{Ni}^{2+}\right]=1 \mp 2 \delta
$$

and

$$
\left[\mathrm{Ni}^{3+}\right]=1 \pm 2 \delta-x
$$

where square brackets denote the number of species per formula unit. The validity of Eq. (2) is based on the assumption that iron is always in the trivalent charge state as revealed by the present Mössbauer spectra (see Mössbauer spectroscopy section) and discussion below. The close agreement of $\left[\mathrm{Ni}^{2+}\right]$ and $\left[\mathrm{Ni}^{3+}\right]$ could give rise to charge ordering and to the formation of some kind of lower symmetry structure. Indeed, charge ordering in $\mathrm{La}_{3} \mathrm{Ni}_{2} \mathrm{O}_{7-\delta}$ at low temperatures has already been discussed by Taniguchi et al. [38] where it was proposed that ordering of electronic charge on nickel was induced by ordering of oxygen vacancies. In the same context, electrical conductivity, which is intimately related with electronic materials properties, has given clear evidence of a transition from temperature-activated behavior to metal-type conduction at high temperatures with reported transition temperatures of $550 \mathrm{~K}[1,18]$ and $600 \mathrm{~K}[19]$.

As evidenced by the RT Mössbauer spectra, $\mathrm{Fe}^{3+}$ cations are almost evenly distributed between the two nonequivalent $\mathrm{Ni1}$ - and Ni2-sites for Ni/Fe in the lattice, Table 2 . This can easily be explained as follows. During their synthesis, samples have been exposed to high temperatures (up to $1373 \mathrm{~K}$ ) where according to the above discussion there is only one unique site for $\mathrm{Ni} / \mathrm{Fe}$ and the Fe dopant will be randomly distributed on this unique site. Electronic charge ordering on the nickel cations leading to less symmetric structure occurs at much lower temperatures where $\mathrm{Fe}^{3+}$ cations are not mobile anymore and, due to their random distribution on available sites, show up in almost equal proportions on the Ni1- and Ni2-sites which occur in equal numbers in the alternative structures previously discussed, Tables 4-6 and Fig. 3. Due to their fixed valence (see Mössbauer spectroscopy section) and discussion below, $\mathrm{Fe}^{3+}$ cations are not part of the electronic ordering process and, thus, serve as "spectators" of the structural changes induced by the evolving electronic charge order-disorder.

In an ideally stoichiometric system, where $x=0$ and $\delta=0, \mathrm{Ni}^{2+}$ and $\mathrm{Ni}^{3+}$ ions are present in exactly equal numbers, Eq. (2), and distributed over the two nonequivalent sites, Ni1 and Ni2, of the structure. Thus, two limiting cases of the cation distribution are to be considered. In one case cation distribution (I) - all sites of Ni1type are occupied by (all) $\mathrm{Ni}^{2+}$ ions and, correspondingly, all $\mathrm{Ni2}$-sites are occupied by (all) $\mathrm{Ni}^{3+}$ ions. In the case of cation distribution (II), all Nil-sites are occupied by $\mathrm{Ni}^{3+}$ and all $\mathrm{Ni2}$-sites by $\mathrm{Ni}^{2+}$. In both situations, different, but single-valued electric field gradients (EFG) are expected at the two inequivalent sites of the structure due to the fully ordered distribution of charges in the lattice. However, already the introduction of $\mathrm{Fe}^{3+}$ ions into sites of the $\mathrm{Ni}^{2+}$ sublattice will create charge disorder which will cause a distribution of EFGs at both sites leading to line broadening. The variable oxygen content - deficit or excess - is associated with changing concentrations of oxygen anions and changing amounts of $\mathrm{Ni}^{3+}$ and $\mathrm{Ni}^{2+}$ cations. This will also contribute to charge disorder in the lattice and, hence, contribute to line broadening in mixed crystals with $x>0$ and $|\delta|>0$. Thus, charge disorder - in addition to absorber thickness - explains the larger line widths for the sample with the higher dopant level, Table 2.

In an alternative explanation for the observation of two sites for $\mathrm{Fe} / \mathrm{Ni}$ in $\mathrm{La}_{3} \mathrm{Ni}_{2-x} \mathrm{Fe}_{x} \mathrm{O}_{7 \pm \delta}$, the possibility is to be 
envisaged that a temperature-dependent reconstruction (intergrowth) of the Ruddlesden-Popper structure may occur. Locally, three perovskite-type layers of iron/nickel atoms may be formed, like in $\mathrm{La}_{4} \mathrm{Ni}_{3-x} \mathrm{Fe}_{x} \mathrm{O}_{10-\delta}$, which would provide two inequivalent sites for nickel (iron). With increasing temperatures, the local three-layer intergrowth $(n=3)$ could change to the higher symmetric $n=$ 2 two-layer structure of $\mathrm{La}_{3} \mathrm{Ni}_{2} \mathrm{O}_{7}$. Such a structural complexity could be a consequence of the fact that for the off-stoichiometric, iron-doped $\mathrm{La}_{3} \mathrm{Ni}_{2-x} \mathrm{Fe}_{x} \mathrm{O}_{7 \pm \delta}$ $(\delta>0, x>0)$ the number of $\mathrm{Ni}^{3+}$ and $\mathrm{Ni}^{2+}$ cations no longer obeys the ideal 1:1 ratio but, instead, is given by $\left[\mathrm{Ni}^{3+}\right]:\left[\mathrm{Ni}^{2+}\right]=1 \mp$ $(x \mp 4 \delta) /(1 \mp 2 \delta)$. In this context, it is also interesting to recall Mössbauer results reported for $\mathrm{La}_{4} \mathrm{Ni}_{3-x} \mathrm{Fe}_{x} \mathrm{O}_{10-\delta}$ with $x=0.03$ [25]. Here, the two quadrupole doublets at RT show splittings of $0.43 \mathrm{~mm} \cdot \mathrm{s}^{-1}$ and $0.95 \mathrm{~mm} \cdot \mathrm{s}^{-1}$ which is very close to the RT $Q S$-values observed for $\mathrm{La}_{3} \mathrm{Ni}_{2-x} \mathrm{Fe}_{x} \mathrm{O}_{7 \pm \delta}$ in the present study, Table 2. However, the above scenario is difficult to accept in view of the fact that diffusional motion of all cations, $\mathrm{La}, \mathrm{Ni}$, and $\mathrm{Fe}$, would be required for changing the local intergrowth situation. This conclusion is also supported by experience gathered by many authors in the (sluggish) high-temperature synthesis of $\mathrm{La}_{3} \mathrm{Ni}_{2} \mathrm{O}_{7 \pm \delta}$, see e. g. Refs. $[7,8,11]$.

The discussion of the results from $\mathrm{X}$-ray diffraction in Crystal structure section has led to the successful identification of several space groups which provide two nonequivalent sites for $\mathrm{Ni} / \mathrm{Fe}$ in equal numbers. It must be admitted, however, that a final decision about the prevailing structure type could not be reached. Therefore, in the following another approach will be taken by considering the ${ }^{57} \mathrm{Fe}$ quadrupolar interactions at the two inequivalent sites in $\mathrm{La}_{3} \mathrm{Ni}_{2} \mathrm{O}_{7}$. In this discussion it will be assumed that the electric field gradients at the iron nuclei, Eq. (1), arise from the so-called lattice contribution, $V_{\alpha a}$ (latt), i. e. from charges located on the ions surrounding the Mössbauer atom in the crystal lattice. Thus, the framework of the point charge model, the EFGs at the two sites for iron can be calculated in the principal axis system according to [29]:

$$
\begin{aligned}
V_{\alpha \alpha} & =\left(1-\gamma_{\infty}\right) V_{\alpha \alpha}(\text { latt })= \\
& =\frac{e\left(1-\gamma_{\infty}\right)}{4 \pi \varepsilon_{0}} \sum_{i} z_{i}\left(3 \alpha_{i}^{2}-r_{i}^{2}\right) r_{i}^{-5}
\end{aligned}
$$

Here, the summation extends over the surrounding lattice ions of charge number $z_{\mathrm{i}}$ and $\left(1-\gamma_{\infty}\right)$ and $\varepsilon_{0}$ denote the Sternheimer factor and the vacuum permittivity, respectively. The lattice EFGs were calculated using the UNISOFT program package [39] and quadrupole splittings were obtained by using a Sternheimer factor for $\mathrm{Fe}^{3+}$ ions of $1-\gamma_{\infty}=10.42$ [40] and a quadrupole moment of $Q=0.209 \cdot 10^{-28} \mathrm{~m}^{2}[41]$.

In an approximation to the complex situation in real $\mathrm{La}_{3} \mathrm{Ni}_{2-x} \mathrm{Fe}_{x} \mathrm{O}_{7 \pm \delta}$ solid solutions, the EFGs at the Ni1- and Ni2-sites have been calculated for an ideal rigid $\mathrm{La}_{3} \mathrm{Ni}_{2} \mathrm{O}_{7}$ lattice $(x=0, \delta=0)$ employing the crystallographic $\mathrm{RT}$ data of $\mathrm{La}_{3} \mathrm{Ni}_{2} \mathrm{O}_{7}$ obtained from the Rietveld refinements partially reported in Tables 5 and 6 . In all cases, the assumption was made that the formal charge number of oxygen is -2 . In the case of the Fmmm space group it was assumed that all $\mathrm{Ni}$-sites are occupied by nickel cations possessing an average charge of $+2.5-$ corresponding to no charge ordering. For the lower-symmetric space groups, the two above defined cation distributions, (I) and (II), have been considered with charge numbers +2 for $\mathrm{Ni}^{2+}$ and +3 for $\mathrm{Ni}^{3+}$ and $\mathrm{La}^{3+}$. Table 7 reports the results of these calculations according 
to Eqs. (1) and (3). It is to be noted that the calculations neither account for $\mathrm{Fe}^{3+}$ cations introduced into the lattice by doping nor for possible deviations from exact stoichiometry. Because of their small numbers and their random distribution, it can be expected that the iron dopants and defects will not influence significantly the average electric field gradients at cation nickel sites, but will lead to a distribution of quadrupole interactions about the structure-determined averages.

As can be seen from Table 7 these admittedly simplistic point charge calculations, which also neglect lattice relaxation around the nuclear Fe probes and any effect of chemical bonding of the ferric cations, successfully yield ${ }^{57} \mathrm{Fe}$ quadrupole splittings of the right order of magnitude, i.e. $0.1<$ $\mathrm{QS} / \mathrm{mm} \cdot \mathrm{s}^{-1}<1$.
Calculated quadrupole splittings in the orthorhombic space groups $\mathrm{Cmmm}$ and Cmma, Table 7, are in reasonable agreement with the experimental splittings of $Q S\left(\mathrm{Fe}_{\mathrm{B}}\right) \approx 0.95 \mathrm{~mm} \cdot \mathrm{s}^{-1}$ and $\mathrm{QS}\left(\mathrm{Fe}_{\mathrm{A}}\right) \approx$ $0.45 \mathrm{~mm} \cdot \mathrm{s}^{-1}$, Table 2 , for both types of cation distributions. However, calculated QS-values are always found smaller than experimental ones by about $20 \%$, Table 7 . In view of the deficiencies of the point charge model in general and the simplifying assumptions made in the calculations, such deviations cannot be unexpected. In contrast, for orthorhombic Bmmb no acceptable agreement is observed between experiment and calculated values. In addition to consideration of the absolute values of quadrupolar interactions, special relevance is attributed to the ratio of splittings, $R_{\mathrm{Q}}=\mathrm{QS}\left(\mathrm{Fe}_{\mathrm{B}}\right) / \mathrm{QS}\left(\mathrm{Fe}_{\mathrm{A}}\right)$, because of possible error cancellation in the calculations.

Table 7

Quadrupolar interactions in $\mathrm{La}_{3} \mathrm{Ni}_{2} \mathrm{O}_{7} \cdot{ }^{57} \mathrm{Fe}$ quadrupole splitting, $\mathrm{QS}$, and splitting ratios $R_{\mathrm{Q}}$, at the nickel sites of $\mathrm{La}_{3} \mathrm{Ni}_{2} \mathrm{O}_{7}$ for space groups Fmmm, Cmmm, Cmma, and Bmmb and for the cation distributions, (I) and (II), which can be adopted by nickel in the lower symmetric structures. Calculations were performed in the framework of the point charge model according to Eqs. $(1,3)$ with lattice parameters taken from respective Rietveld refinements

\begin{tabular}{|c|c|c|c|c|}
\hline Space group & $\begin{array}{c}\text { Cation } \\
\text { distribution }\end{array}$ & Site & $\begin{array}{c}Q S \\
\mathrm{~mm} \cdot \mathrm{s}^{-1}\end{array}$ & $R_{\mathrm{Q}}$ \\
\hline Fmmm & - & $\mathrm{Ni}$ & 0.74 & - \\
\hline \multirow{4}{*}{$\mathrm{Cmmm}$} & (I) & Ni1 & 0.86 & 3.0 \\
\hline & (I) & $\mathrm{Ni} 2$ & 0.29 & \\
\hline & (II) & Ni1 / A & 0.36 & 2.2 \\
\hline & (II) & $\mathrm{Ni2} / \mathrm{B}$ & 0.79 & \\
\hline \multirow{4}{*}{ Cmma } & (I) & $\mathrm{Ni1} / \mathrm{B}$ & 0.81 & 2.3 \\
\hline & (I) & $\mathrm{Ni} 2 / \mathrm{A}$ & 0.35 & \\
\hline & (II) & Nil & 0.28 & 3.1 \\
\hline & (II) & $\mathrm{Ni} 2$ & 0.88 & \\
\hline \multirow{4}{*}{$B m m b$} & (I) & Ni1 & 0.83 & 1.1 \\
\hline & (I) & $\mathrm{Ni} 2$ & 0.75 & \\
\hline & (II) & Ni1 & 0.92 & 1.4 \\
\hline & (II) & $\mathrm{Ni} 2$ & 0.66 & \\
\hline
\end{tabular}


At RT, the experimental ratio assumes values of about $R_{Q}=2.3(x=0.05)$ and $R_{Q}=2.0(x=0.10)$, Table 2 . As can be seen from Table 7 , such values are not consistent with those calculated for $B m m b$ where this ratio amounts to 1.1 or 1.4 for cation distributions (I) and (II), respectively. For $\mathrm{Cmmm}$ (I) as well as for Cmma(II) calculated ratios are significantly larger than the experimental $R_{\mathrm{Q}}$-values. However, for $\mathrm{Cmmm}$ (II) and for Cmma(I) close agreement is observed with calculated ratios of 2.2 and 2.3, respectively, indicated in "bold" in Table 7. Because we see no further means for differentiation between the two structures, we arrive at the conclusion that space group $\mathrm{Cmmm}$ with a cation distribution of type (II) as well as space group Cmma with cation distribution (I) represent good structural models for $\mathrm{La}_{3} \mathrm{Ni}_{2-x} \mathrm{Fe}_{x} \mathrm{O}_{7 \pm \delta}$ solid solutions at RT.

In the present combined approach involving diffraction and spectroscopic work, A- and B-sites can be even be assigned to the Ni1- and Ni2-sites in these space groups according to the quadrupole splittings calculated for the respective types of cation distribution, see Table 7. This conclusion on the crystal structure of $\mathrm{La}_{3} \mathrm{Ni}_{2-x} \mathrm{Fe}_{x} \mathrm{O}_{7 \pm \delta}$, which is in agreement with the space groups arrived at on the basis of general structural considerations and $\mathrm{Ri}$ etveld refinements of the materials, narrows down considerably the number of possible combinations of space groups and cation distributions of $\mathrm{La}_{3} \mathrm{Ni}_{2-x} \mathrm{Fe}_{x} \mathrm{O}_{7 \pm \delta}$ at RT.

\section{Conclusions}

At RT, local probe ${ }^{57} \mathrm{Fe}$ Mössbauer spectroscopy has provided indisputable evidence for the existence of two nonequivalent sites for $\mathrm{Fe}^{3+}$ in $\mathrm{La}_{3} \mathrm{Ni}_{2-x} \mathrm{Fe}_{x} \mathrm{O}_{7 \pm \delta}$ with site populations closely corresponding to the 1:1 ratio. This unexpected result is in contrast to the hitherto existing structure determinations of $\mathrm{La}_{3} \mathrm{Ni}_{2} \mathrm{O}_{7 \pm \delta}$. The latter assumed space groups $\mathrm{Fmmm}$ or $\mathrm{Cmcm}$ (Amam) which both provide only a single unique site for nickel/iron. In view of the spectroscopic findings, the RT structure of $\mathrm{La}_{3} \mathrm{Ni}_{2-x} \mathrm{Fe}_{x} \mathrm{O}_{7 \pm \delta}$ has been reconsidered and X-ray diffraction patterns for samples with $x=0,0.05$, and 0.10 have been measured and refined by the Rietveld method. The interest was in the iden-

tification of alternative structural models which could replace the previously used space groups. From general considerations, we have selected the orthorhombic space groups Cmma, Cmmm, and Bmmb which fulfill the spectroscopic requirements of providing two sites in equal numbers for $\mathrm{Ni} / \mathrm{F}$. According to Rietveld refinements, Cmma and Cmmm can be considered the preferred space groups. Calculations of the quadrupolar interactions at the iron nuclei in $\mathrm{La}_{3} \mathrm{Ni}_{2} \mathrm{O}_{7}$ in the framework of the point charge model have confirmed this conclusion and provided additional information on the specific distribution of $\mathrm{Ni}^{2+}$ and $\mathrm{Ni}^{3+}$ cations in these structures at RT.

\section{Acknowledgements}

K.-D.B. and P.G. would like to thank the Volkswagen-Foundation and the State of Lower Saxony (Germany) for financial support of the present work. E.K. and V.C. acknowledge support of their work by the Ministry of Education and Science of the Russian Federation. A.F. is grateful to the Deutsche Forschungsgemeinschaft (DFG) for financial support in the frame of grant FE928/7-1. Thanks are also due to Prof. Th. Gesing 
(U Bremen, Germany) for chemical EDX analyses of samples. E.K and V. Ch. work was supported by Act 211 Government of the Russian Federation, agreement 02.A03.21.0006.

\section{References}

1. Amow G, Davidson IJ, Skinner SJ. A comparative study of the Ruddlesden-Popper series, $\mathrm{La}_{n+1} \mathrm{Ni}_{n} \mathrm{O}_{3 n+1}(n=1,2$ and 3), for solid-oxide fuel-cell cathode applications. Solid State Ionics. 2006;177(13-14):1205-10.

DOI: 10.1016/j.ssi.2006.05.005.

2. Goettler R, Xing Z, Xue L, Hill M. Evaluation of Ruddlesden-Popper nickelate cathodes for higher temperature SOFC. Ceramic Engineering and Science Proceedings. 2008;28(4):183-94.

DOI: 10.1002/9780470339534.ch18.

3. Takahashi S, Nishimoto S, Matsuda M, Miyake M, Electrode properties of the Ruddlesden-Popper series, $\mathrm{La}_{n+1} \mathrm{Ni}_{n} \mathrm{O}_{3 n+1}(n=1,2$, and 3), as intermediate-temperature solid oxide fuel cells. J. Am. Ceram. Soc. 2010;93(8):2329-33.

DOI: 10.1111/j.1551-2916.2010.03743.x.

4. Woolley RJ, Skinner SJ. Novel $\mathrm{La}_{2} \mathrm{NiO}_{4+\delta}$ and $\mathrm{La}_{4} \mathrm{Ni}_{3} \mathrm{O}_{10-\delta}$ composites for solid oxide fuel cell cathodes. J. Power Sources. 2013;243:790-95.

DOI: 10.1016/j.jpowsour.2013.06.106.

5. Woolley RJ, Skinner SJ. Functionally graded composite $\mathrm{La}_{2} \mathrm{NiO}_{4+\delta}$ and $\mathrm{La}_{4} \mathrm{Ni}_{3} \mathrm{O}_{10-\delta}$ solid oxide fuel cell cathodes. Solid State Ionics. 2014;255:1-5.

DOI: 10.1016/j.ssi.2013.11.041.

6. Brisi C., Vallino M, Abbattista F. Composition and structure of two hitherto unidentified phases in the system $\mathrm{La}_{2} \mathrm{O}_{3}-\mathrm{NiO}-\mathrm{O}$. J. Less Common Metals, 1981;79(2): 215-19.

DOI: 10.1016/0022-5088(81)90070-9.

7. Drennan J, Tavares CP, Steele BCH. An electron microscope investigation of phases in the system La-Ni-O. Mat. Res. Bull. 1981;17(5):621-26.

DOI: 10.1016/0025-5408(82)90044-7.

8. Odier P, Nigara Y, Coutures J, Sayer M. Phase relations in the La-Ni-O system: Influence of temperature and stoichiometry on the structure of $\mathrm{La}_{2} \mathrm{NiO}_{4}$. J. Solid State Chem. 1985;56(1):32-40.

DOI: 10.1016/0022-4596(85)90249-X.

9. Ram RM, Ganapathi L, Ganguly P, Rao CNR. Evolution of three-dimensional character across the $\mathrm{La}_{n+1} \mathrm{Ni}_{n} \mathrm{O}_{3 n+1}$ homologous series with increase in $n$. J. Solid State Chem. 1986;63(2):139-47.

DOI: 10.1016/0022-4596(86)90163-5.

10. Sreedhar K, McElfresh M, Perry D, Kim D, Metcalf P, Honig JM. Low-temperature electronic properties of the $\mathrm{La}_{n+1} \mathrm{Ni}_{n} \mathrm{O}_{3 n+1}(n=2,3$, and $\infty)$ system: evidence for a crossover from fluctuating-valence to Fermi-liquid-like behavior. J. Solid State Chem. 1994;110(2):208-15.

DOI: $10.1006 /$ jssc.1994.1161. 
11. Zhang Z, Greenblatt M, Goodenough JB. Synthesis, structure, and properties of the layered perovskite $\mathrm{La}_{3} \mathrm{Ni}_{2} \mathrm{O}_{7-\delta}$. J. Solid State Chem. 1994;108(2):402-09.

DOI: $10.1006 /$ jssc.1994.1059.

12. Carvalho MD, Costa FMA, Pereira IS, Wattiaux A, Bassat JM, Grenier JC, Pouchard M. New preparation method of $\mathrm{La}_{n+1} \mathrm{Ni}_{n} \mathrm{O}_{3 n+1-\delta}(n=2,3)$. J. Mater. Chem. 1997;7(10):2107-11.

DOI: 10.1039/A702424J.

13. Sasaki H, Harashina H, Taniguchi S, Kasai M, Kobayashi Y, Sato M, Sakata M. Structural studies on the phase transition of $\mathrm{La}_{3} \mathrm{Ni}_{2} \mathrm{O}_{6.92}$ at about 550, K. J. Phys. Soc. Jpn. 1997;66(6):1693-97.

DOI: $10.1143 /$ jpsj.66.1693.

14. Ling CD, Argyriou DN, Wu G, Neumeier JJ. Neutron diffraction study of $\mathrm{La}_{3} \mathrm{Ni}_{2} \mathrm{O}_{7}$ : Structural relationships among $n=1,2$, and 3 phases $\mathrm{La}_{n+1} \mathrm{Ni}_{n} \mathrm{O}_{3 n+1}$. J. Solid State Chem. 2000;152(2):517-25.

DOI: $10.1006 /$ jssc.2000.8721.

15. Voronin VI, Berger IF, Cherepanov VA, Gavrilova LY, Petrov AN, Ancharov AI, Nikitenko SG. Neutron diffraction, synchrotron radiation and EXAFS spectroscopy study of crystal structure peculiarities of the lanthanum nickelates $\mathrm{La}_{n+1} \mathrm{Ni}_{n} \mathrm{O}_{y}(n=$ 1, 2, 3). Nucl. Instrum. Methods Phys. Res., Sect. A. 2001;470(1-2):202-209. DOI: 10.1016/S0168-9002(01)01036-1.

16. Bannikov DO, Cherepanov VA. Thermodynamic properties of complex oxides in the La-Ni-O system. J. Solid State Chem. 2006;179(8):2721-27.

DOI: 10.1016/j.jssc.2006.05.026.

17. Savchenko VF, Ivashkevich LS,. Lubkina IYa, Russ. J. Inorg. Chem. 1988;33:30-33.

18. Kobayashi Y, Taniguchi S, Kasai M, Sato M, Nishioka, Kontani M. Transport and magnetic properties of $\mathrm{La}_{3} \mathrm{Ni}_{2} \mathrm{O}_{7-\delta}$ and $\mathrm{La}_{4} \mathrm{Ni}_{3} \mathrm{O}_{10-\delta}$. J. Phys. Soc. Jpn. 1996;65(12):3978-82. DOI: DOI.org/10.1143/jpsj.65.3978.

19. Gervais F, Odier P, Nigara Y. Plasmon behavior at the "semiconductor-metal" transition in $\mathrm{La}_{2} \mathrm{NiO}_{4}$ and $\mathrm{La}_{3} \mathrm{Ni}_{2} \mathrm{O}_{7}$. Solid State Commun. 1985;56(4):371-74. DOI: 10.1016/0038-1098(85)90405-3.

20. Zinkevich M, Solak N, Nitsche H, Ahrens M, Aldinger F. Stability and thermodynamic functions of lanthanum nickelates. J. Alloys Compd. 2007; 438(1-2):92-99. DOI: 10.1016/j.jallcom.2006.08.047.

21. Fontcuberta J, Longworth G, Goodenough JB. Magnetic order or charge-density wave in $\mathrm{La}_{2} \mathrm{NiO}_{4}$ by Mössbauer spectroscopy. Phys. Rev. B. 1984;30(11):6320.

DOI: 10.1103/PhysRevB.30.6320.

22. Tsipis EV, Naumovich EN, Patrakeev MV, Waerenborgh JC, Pivak YV, Gaczyński P, Kharton VV. Oxygen non-stoichiometry and defect thermodynamics in $\mathrm{La}_{2} \mathrm{Ni}_{0.9} \mathrm{Fe}_{0.1} \mathrm{O}_{4+\delta}$. J. Phys. Chem. Solids. 2007;68(7):1443-55.

DOI: 10.1016/j.jpcs.2007.04.006.

23. Klande T, Efimov K, Cusenza S, Becker KD, Feldhoff A. Effect of doping, microstructure, and $\mathrm{CO}_{2}$ on $\mathrm{La}_{2} \mathrm{NiO}_{4+\delta}$-based oxygen-transporting materials. J. Solid State Chem. 2011;184(12):3310-18.

DOI: $10.1016 /$ j.jssc.2011.10.019. 
24. Klande T, Cusenza S, Gaczyński P, Becker KD, Dörrer L, Borchardt G, Feldhoff A. In-situ Mössbauer studies of ${ }^{57} \mathrm{Fe}$-doped Ruddlesden-Popper type lanthanum nickel oxides. Solid State Ionics, 2012;222-223:8-15.

DOI: 10.1016/j.ssi.2012.06.019.

25. Carvalho MD, Wattiaux A, Ferreira LP, Bassat JM. Mössbauer investigation of ${ }^{57} \mathrm{Fe}$ doped $\mathrm{La}_{4} \mathrm{Ni}_{3} \mathrm{O}_{10 \pm y}$ phases. J. Solid State Chem. 2009;182(1):60-64.

DOI: $10.1016 /$ j.jssc.2008.10.006.

26. Tsipis EV, Patrakeev MV, Waerenborgh JC, Pivak YV, Markov AA, Gaczyński P, Kharton VV. Oxygen non-stoichiometry of $\mathrm{Ln}_{4} \mathrm{Ni}_{2.7} \mathrm{Fe}_{0.3} \mathrm{O}_{10-\delta}(\mathrm{Ln}=\mathrm{La}, \mathrm{Pr})$. J. Solid State Chem. 2007;180(6):1902-10.

DOI: 10.1016/j.jssc.2007.04.025.

27. Rodriguez-Carvajal J. Commission on powder diffraction (IUCr). Newsletter, 2001;26:12.

28. Lagarec K, Rancourt DG. RECOIL, Mössbauer spectral analysis software for windows (version 1.02). Ottawa: Department of Physics, University of Ottawa;1998.

29. Gütlich P, Bill E, Trautwein AX. Mössbauer Spectroscopy and Transition Metal Chemistry. Berlin, Heidelberg: Springer; 2011.568 p.

DOI: 10.1007/978-3-540-88428-6.

30. Menil F. Systematic trends of the ${ }^{57} \mathrm{Fe}$ Mössbauer isomer shifts in $\left(\mathrm{FeO}_{\mathrm{n}}\right)$ and $\left(\mathrm{FeF}_{\mathrm{n}}\right)$ polyhedra. Evidence of a new correlation between the isomer shift and the inductive effect of the competing bond TX $(\rightarrow \mathrm{Fe}$ )(where $\mathrm{X}$ is $\mathrm{O}$ or $\mathrm{F}$ and $\mathrm{T}$ any element with a formal positive charge). J. Phys. Chem. Solids. 1985;46(7):763-89.

DOI: 10.1016/0022-3697(85)90001-0.

31. Rancourt DG. Accurate site populations from Mössbauer spectroscopy. Nucl. Instrum. Methods Phys. Res., Sect. B. 1989;44(2):199-210.

DOI: 10.1016/0168-583X(89)90428-X.

32. Boultif A, Louër D. Powder pattern indexing with the dichotomy method. J. Appl. Crystallogr. 2004;37(5):724-31

DOI: $10.1107 /$ S0021889804014876.

33. Visser JW. A fully automatic program for finding the unit cell from powder data. J. Appl. Crystallogr. 1969;2(3):89-95.

DOI: $10.1107 /$ S0021889869006649.

34. Roisnel T, Rodríquez-Carvajal J. WinPLOTR: a windows tool for powder diffraction pattern analysis. In Materials Science Forum (Vol. 378, No. 1, pp. 118-123). Transtec Publications, 1999.

35. Hahn Th. International Tables for Crystallography, Vol. A: Space-group symmetry. $5^{\text {th }}$ ed. Dordrecht: Springer, 2005. $911 \mathrm{p}$.

36. Kraus W, Nolze G. POWDER CELL-a program for the representation and manipulation of crystal structures and calculation of the resulting X-ray powder patterns. J. Appl. Crystallogr. 1996;29(3):301-03.

DOI: $10.1107 /$ S0021889895014920.

37. Shannon RD. Revised effective ionic radii and systematic studies of interatomic distances in halides and chalcogenides. Acta Cryst. 1976; A32:751-67.

DOI: $10.1107 /$ S0567739476001551. 
38. Taniguchi S, Nishikawa T, Yasui Y, Kobayashi Y, Takeda J, Shamoto SI, Sato M. Transport, magnetic and thermal properties of $\mathrm{La}_{3} \mathrm{Ni}_{2} \mathrm{O}_{7-\delta}$. J. Phys. Soc. Jpn. 1995;64(5):1644-50.

DOI: DOI.org/10.1143/jpsj.64.1644.

39. Eckold G. UNISOFT - A Program Package for Lattice-Dynamical Calculations: User Manual, 2nd rev. ed. Jülich: Jülich Forschungszentrum, 1992.

40. Stevens JG, Dunlap BD. Nuclear moments and moment ratios as determined by Mössbauer spectroscopy. J. Phys. Chem. Ref. Data, 1976;5(4):1093-122. DOI: $10.1063 / 1.555541$.

41. Liverts EZ, Zhetbaev AK. Sternheimer Quadrupole Factors in Ferric Compounds. Phys. Status Solidi B. 1982;111(2):469-475.

DOI: $10.1002 /$ pssb.2221110207. 